OPEN ACCESS

Edited by:

Grigori Enikolopov,

Stony Brook University, USA

Reviewed by:

Armen Saghatelyan,

Université Laval, Canada

Eric D. Laywell,

Florida State University, USA

*Correspondence:

Alino Martinez-Marcos

alino.martinez@uclm.es

Specialty section: This article was submitted to

Neurogenesis,

a section of the journal

Frontiers in Neuroscience

Received: 13 December 2015 Accepted: 06 May 2016

Published: 30 May 2016

Citation:

De la Rosa-Prieto C, Saiz-Sanchez D,

Ubeda-Banon I, Flores-Cuadrado A

and Martinez-Marcos A (2016)

Neurogenesis, Neurodegeneration,

Interneuron Vulnerability, and

Amyloid- $\beta$ in the Olfactory Bulb of APP/PS1 Mouse Model of Alzheimer's

Disease. Front. Neurosci. 10:227.

doi: 10.3389/fnins.2016.00227

\section{Neurogenesis, Neurodegeneration, Interneuron Vulnerability, and Amyloid- $\beta$ in the Olfactory Bulb of APP/PS1 Mouse Model of Alzheimer's Disease}

\author{
Carlos De la Rosa-Prieto, Daniel Saiz-Sanchez, Isabel Ubeda-Banon, \\ Alicia Flores-Cuadrado and Alino Martinez-Marcos *
}

Neuroplasticity and Neurodegeneration Laboratory, CRIB, Ciudad Real Medical School, Universidad de Castilla-La Mancha, Ciudad Real, Spain

Alzheimer's disease $(A D)$ is the most prevalent neurodegenerative disease, mostly idiopathic and with palliative treatment. Neuropathologically, it is characterized by intracellular neurofibrillary tangles of tau protein and extracellular plaques of amyloid $\beta$ peptides. The relationship between $A D$ and neurogenesis is unknown, but two facts are particularly relevant. First, early aggregation sites of both proteinopathies include the hippocampal formation and the olfactory bulb (OB), which have been correlated to memory and olfactory deficits, respectively. These areas are well-recognized integration zones of newly-born neurons in the adult brain. Second, molecules, such as amyloid precursor protein (APP) and presenilin-1 are common to both AD etiology and neurogenic development. Adult neurogenesis in AD models has been studied in the hippocampus, but only occasionally addressed in the $\mathrm{OB}$ and results are contradictory. To gain insight on the relationship between adult neurogenesis and $A D$, this work analyzes neurogenesis, neurodegeneration, interneuron vulnerability, and amyloid- $\beta$ involvement in the $\mathrm{OB}$ of an $\mathrm{AD}$ model. Control and double-transgenic mice carrying the APP and the presenilin-1 genes, which give rise amyloid $\beta$ plaques have been used. BrdU-treated animals have been studied at 16, 30, 43, and 56 weeks of age. New-born cell survival (BrdU), neuronal loss (using neuronal markers NeuN and PGP9.5), differential interneuron (calbindin-, parvalbumin-, calretinin- and somatostatin-expressing populations) vulnerability, and involvement by amyloid $\beta$ have been analyzed. Neurogenesis increases with aging in the granule cell layer of control animals from 16 to 43 weeks. No neuronal loss has been observed after quantifying NeuN or PGP9.5. Regarding interneuron population vulnerability: calbindin-expressing neurons remains unchanged; parvalbumin-expressing neurons trend to increase with aging in transgenic animals; calretinin-expressing neurons increase with aging in transgenic mice and decrease in control animals and neurogenesis is higher in control as compared to transgenic animals at given ages, finally; somatostatin-expressing neurons of transgenic mice decrease with aging and as compared to controls. Amyloid $\beta$ aggregates with aging in the granule cell layer, which may be related to the particular involvement of somatostatin-expressing cells.

Keywords: adult neurogenesis, calbindin, calretinin, parvalbumin, somatostatin 


\section{INTRODUCTION}

Alzheimer's disease (AD) is the most prevalent neurodegenerative disease and the main cause of dementia (Reiman, 2014). It is characterized by cognitive deficits and nowadays treatments are palliative. Two associated proteinopathies yield aggregates into the brain: tau protein that form intracellular neurofibrillary tangles and insoluble forms of amyloid $\beta$ (A $\beta)$ peptides that assembles into extracellular plaques (Goedert and Spillantini, 2006; Ballard et al., 2011). Neuropathological staging of these deposits show that early sites of involvement include the $\mathrm{OB}$ and the hippocampal formation (Ohm and Braak, 1987; Braak and Braak, 1991; Braak et al., 2006; Attems et al., 2014; Braak and Del Trecidi, 2015). These areas correlate with initial symptoms, namely olfactory (Devanand et al., 2015) and declarative memory deficits (Jahn, 2013).

Interestingly, the subventricular zone of the lateral ventricles (SVZ) and the hippocampal subgranular zone (SGZ) were described as the two main neurogenic niches giving rise to newlyborn neurons migrating and integrating into the adult olfactory bulb $(\mathrm{OB})$ and the dentate gyrus (DG) of the hippocampus, respectively (Altman, 1962; Altman and Das, 1965; Luskin, 1993; Lois and Alvarez-Buylla, 1994). Decades later, the functional significance of new neurons integrated into adult OB (Lepousez et al., 2013) and DG (Deng et al., 2010) is only partially known.

$\mathrm{AD}$ and adult neurogenesis are not only linked by common sites where early pathology occurs and newly-born neurons integrate in the preexisting circuitry, but share a number of common molecules to both processes (Kaneko and Sawamoto, 2009; Lazarov and Marr, 2010, 2013; Lazarov et al., 2010; $\mathrm{Mu}$ and Gage, 2011; Winner et al., 2011). Increasing evidence suggest that molecular players in Alzheimer disease, including amyloid precursor protein (APP) and presenilin 1 (PS1) and its metabolites, play a role in adult neurogenesis (Lazarov and Marr, 2010). Soluble APP $\alpha$ regulate neural progenitor cell proliferation. Thus, miscleavage of APP would readily influence on developmental and postnatal neurogenesis, which could contribute to cognitive deficits characterizing $\mathrm{AD}$ (Lazarov and Demars, 2012). On the other hand, PS1 is not only prominently expressed in the embryonic brain but is also a crucial regulator of Notch and Wnt signaling (Winner et al., 2011), key pathways in neural differentiation. In addition, polymorphisms in the apolipoprotein $\mathrm{E}$ (apoE, the $\varepsilon 4$ isoform) gene show the most significant effects on relative genetic risk of AD. Experiments in transgenic mice carrying human apoE4 have shown apoptosis of neural progenitor cells after environmental enrichment suggesting that apoE4 is somewhat compromising neurogenesis (Levi and Michaelson, 2007).

Data on neurogenic rate changes in $\mathrm{AD}$ models are quite variable depending on the different transgenic mice, experimental conditions, and markers analyzed; and, it is

Abbreviations: $\mathrm{A} \beta$, amyloid $\beta$; $\mathrm{AD}$, Alzheimer's disease; $\mathrm{APP}$, amyloid precursor protein; BrdU, bromodeoxyuridine; $\mathrm{CB}$, calbindin; $\mathrm{CR}$, calretinin; DG, dentate gyrus; ePL, external plexiform layer; GL, glomerular layer; GrL, granule cell layer; iPL, internal plexiform layer, MOB, main olfactory bulb; NeuN, Fox3-NeuN; OB, olfactory bulb; PS1, presenilin 1; PV, parvalbumin; SGZ, subgranular zone; SST, somatostatin; SVZ, subventricular zone; TG, transgenic; WT, wild type. not always obvious to distinguish it from changes due to physiological aging (Lazarov and Marr, 2010; Winner et al., 2011). Data in the model used in the present study (APPswe/PS1 $\triangle \mathrm{E} 9$ ) show reduced hippocampal neurogenesis (Verret et al., 2007; Niidome et al., 2008). This impairment in neurogenesis take place early in life long before amyloid deposition suggesting that the decrease of neurogenic rate may be a contributor factor rather than a result of neural dysfunction (Demars et al., 2010). Interestingly, the reduction in neuroblasts, as confirmed by quantitative Western blot analysis of doublecortin content, was restricted to the hippocampal but not to the OB neurogenic system (Zhang et al., 2007).

Data from different authors and our previous results indicate a differential interneuron vulnerability in postmortem tissue from Alzheimer's patients and in transgenic mice model (Fonseca and Soriano, 1995; Solodkin et al., 1996; Brady and Mufson, 1997; Leuba et al., 1998; Iritani et al., 2001; Saiz-Sanchez et al., 2010, 2012, 2013, 2015, 2016).

Therefore, the present study aims at characterizing the neurogenic process in the OB of APP/PS1 mice by analyzing the neurogenic and neurodegeneration rates and the role $A \beta$ in the survival of new and preexisting interneuron populations.

\section{MATERIALS AND METHODS}

\section{Experimental Animals}

For this study, 20 female hemizygous double transgenic mice (B6C3-Tg-APPswe, PSEN1dD9-85Dbo/J) model of AD and 20 female non-carrier mice have been used (004462, The Jackson Laboratory, USA). These transgenic mice express a chimeric mouse/human APP (Mo/HuAPP695swe) and a mutant human presenilin 1 (PS1-dD9), each controlled by independent mouse prion protein (PrP) promoter elements (Jankowsky et al., 2001, 2004). The APPswe/PSEN1dD9 (APPxPS1) mouse model is characterized by increasing $A \beta$ levels with aging (Jankowsky et al., 2004; Van Groen et al., 2006). Four experimental groups of five transgenic and five non-carrier animals were stablished according to survival times (16, 30, 43, and 56 weeks). The animals were housed on a standard $12 / 12 \mathrm{~h}$ light/dark cycle, at $21^{\circ} \mathrm{C}$ with food and water ad libitum. All of the animal research procedures described herein were in agreement with European (Directive 2010/63/EU) and Spanish (RD 53/2013) legislation on the protection of animals used for scientific purposes. All experiments described were approved by the Ethical Committee of Animal Research of the University of Castilla-La Mancha (grant BFU2010-15729).

\section{Bromodeoxyuridine Administration, Perfusion, and Sectioning}

BrdU (5-bromo-2'-deoxyuridine, Fluka, Madrid, Spain) administration included four i.p. doses (at 2-h intervals) of 10 $\mathrm{mg} / \mathrm{mL} \mathrm{BrdU}$ in phosphate-buffered saline (PBS, $0.15 \mathrm{M} \mathrm{NaCl}$, $0.01 \mathrm{M}$ sodium phosphate $\mathrm{pH}$ 7.4) totalizing a dose of 200 $\mathrm{mg} / \mathrm{kg}$ in 1 day. This dose was employed following previous results in our laboratory to optimize labeling without increasing apoptosis (Martínez-Marcos et al., 2000a,b; Martinez-Marcos et al., 2005; De La Rosa-Prieto et al., 2009). Two week afterwards, 
animals were anesthetized with a combined dose of ketamine hydrochloride (Ketolar, Parke-Davis, Madrid, Spain, $1.5 \mathrm{~mL} / \mathrm{kg}$, $75 \mathrm{mg} / \mathrm{kg}$ ), and xylazine (Xilagesic, Calier, Barcelona, Spain, $0.5 \mathrm{~mL} / \mathrm{kg}, 10 \mathrm{mg} / \mathrm{kg}$ ) and perfused with saline solution followed by $4 \% \mathrm{w} / \mathrm{v}$ paraformaldehyde fixative in phosphate buffer $(0.1$ $\mathrm{M}$ sodium phosphate $\mathrm{pH}$ 7.2). Brains were postfixed in $4 \%$ $\mathrm{w} / \mathrm{v}$ paraformaldehyde, cryoprotected in $30 \% \mathrm{w} / \mathrm{v}$ sucrose, and the olfactory bulbs frontally sectioned $(50 \mu \mathrm{m})$ using a freezing sliding microtome (Microm HM450). Sections were consecutively collected into 96-well-plates and maintained at $4{ }^{\circ} \mathrm{C}$ in preserving solution (PBS containing $20 \% \mathrm{v} / \mathrm{v}$ glycerol and $30 \% \mathrm{v} / \mathrm{v}$ ethylene glycol) for further processing.

\section{Immunofluorescence Procedures}

Six sections from rostral to caudal $O B$ of each animal were chosen (separated $400 \mathrm{um}$ ) and rinsed overnight with Tris-buffered saline (TBS; $0.15 \mathrm{M} \mathrm{NaCl}, 0.05 \mathrm{M}$ Tris, $\mathrm{HCl} \mathrm{pH} \mathrm{7.6)} \mathrm{and}$ blocked with $10 \% \mathrm{v} / \mathrm{v}$ normal donkey serum (NDS; Vector Laboratories, Burlingame, CA) in TBS for $60 \mathrm{~min}$ at room temperature. Sections were then incubated overnight with rabbit anti-amyloid beta (A $\beta, 1: 250$, Cell Signaling, 2454, MA, USA), goat anti-calretinin (CR, 1:1000, Santa Cruz, sc-11644, CA, USA), monoclonal mouse anti-calbindin D-28k (CB, 1:5000, Swant, 300, Switzerland), goat anti-somatostatin (SST, 1:1000, Santa Cruz, sc-7819, CA, USA), goat anti-parvalbumin (PV,1:2000, Swant, PVG-213, Switzerland), mouse monoclonal PGP9.5 (PGP9.5 13C4/I3C4, 1:1000, abcam, ab8189, Cambridge, MA, USA), or rabbit anti-NeuN (NeuN, 1:500, abcam, ab104225, Cambridge, MA, USA) diluted in TBS with $5 \% \mathrm{v} / \mathrm{v}$ normal goat serum and $0.3 \%$ Triton $\mathrm{X}-100$ at $4^{\circ} \mathrm{C}$. Then, sections were incubated for $2 \mathrm{~h}$ at room temperature with Alexas 488, 555, 568, or 647 anti-multiple species (1:200 in TBS with $2 \%$ of normal goat serum and 0.2\% Triton X-100; Invitrogen, Eugene, OR).

Sections were then rinsed with TBS and incubated in ice-cold paraformaldehyde $4 \% \mathrm{v} / \mathrm{v}$ for $15 \mathrm{~min}$. Rinsed again and incubated in $2 \mathrm{~N} \mathrm{HCL}$ at $37^{\circ}$ during $1 \mathrm{~h}$. After rinsed several times, sections were incubated overnight with mouse anti-BrdU (BrdU,1:40, Dako, M0744, Glostrup, Denmark). Sections were subsequently incubated for $2 \mathrm{~h}$ at room temperature with Alexa 488, antimouse (1:200 in TBS with $2 \%$ of normal goat serum and $0.2 \%$ Triton X-100; Invitrogen, Eugene, OR), and counterstained using DAPI $(1 \mu \mathrm{g} / \mathrm{ml}$ in TBS, Santa Cruz, SC-3598) for $5 \mathrm{~min}$ in the dark.

\section{Analysis of Labeled Cells}

The images of different fluorophores were analyzed using ImageJ and ZEN software from Zeiss using the profile and ortho tools of ZEN software. GraphPad Prism ${ }^{\circledR}$ v.6 (San Diego, CA, USA) was used for statistical analyses. Kolmogorov-Smirnov and Wald-Wolfowitz tests were carried out to analyze the normality and randomness of the sample $(P>0.05)$. Statistical comparisons were performed using an unpaired two-tailed $t$-test, or one-way or two-way ANOVA followed by Bonferroni and Tukey posthoc tests to estimate the significance of differences between age groups, markers, areas, WT, and TG animals. All data are represented as mean \pm SEM. Differences were regarded as statistically significant at ${ }^{*}$ or $\# P<0.05$, ${ }^{* *}$ or $\# \# P<0.01$, ${ }^{* * *}$ or $\# \# P<0.001$, and ${ }^{* * * *} P<0.0001$.

\section{RESULTS}

The aim of the present report has been to study in depth the relationship between adult neurogenesis and $\mathrm{AD}$ by analyzing neurogenic rate, neurodegeneration, interneuron vulnerability, and $\mathrm{A} \beta$ involvement in the $\mathrm{OB}$ of control and transgenic mice over time. The different layers of the main OB (MOB; Figure 1A) have been grouped for analysis: granule $(\mathrm{GrL})$ and internal plexiform (iPL), mitral (ML), and external plexiform (ePL), and glomerular (GL), and nerve (NL) layers (Figure 1B).

\section{Analysis of BrdU-Labeled Cells}

The labeling of BrdU-positive cells was mainly concentrated in the GrL and GL of control and transgenic animals at different ages (Figures 1C-F). The analysis of BrdU-labeled cells over time revealed an increasing trend in the GrL with aging that was statistically significant between 16 (Figure 1C) and 43 (Figure 1D) weeks in control animals (Figure 1G) [Two-way ANOVA genotype vs. age: Interaction $F_{(3,62)}=1.846 ; p=$ 0.1482 ; Age $F_{(3,62)}=3.220 ; p=0.0287$; Genotype $F_{(1,62)}=$ $0.0002612 ; p=0.9872]$. This trend was not observed in the GL (Figure 1G) [Two-way ANOVA genotype vs. age: Interaction $F_{(3,63)}=0.5647 ; p=0.6403 ; \operatorname{Age} F_{(3,63)}=2.676 ; p=0.0547$; Genotype $\left.F_{(1,63)}=7.260 ; p=0.0090\right]$.

Regarding genotype comparison, no clear differences were observed in the GrL, but in the GL, the number of BrdU-labeled cells was in general lower in transgenic (Figure 1F) as compared to control (Figure 1E) animals.

\section{Analysis of NeuN- and PGP9.5-Labeled Cells}

In order to evaluate a possible neuronal loss, two neural markers have been used in the $\mathrm{OB}$ of control and transgenic mice: NeuN has been used to label neurons in GrL (Figures 2A,B) and GL (Figures 2E,F), and PGP9.5 in ML (Figures 2C,D) since not all neural populations are labeled by commercial neural markers (see Supplementary Figure 1) (Bagley et al., 2007; Bianchi et al., 2014).

Statistical analysis showed no significant changes over time and genotype or between control and transgenic animals in the GrL (Figure 2G) [Two-way ANOVA (genotype vs. age): Interaction $F_{(3,28)}=0.7079 ; p=0.5554$; Age $F_{(3,28)}=0.9086$; $p=0.4494 ;$ Genotype $\left.F_{(1,28)}=0.7859 ; p=0.3829\right], \mathrm{ML}$ [Two-way ANOVA (genotype vs. age): Interaction $F_{(3,28)}=$ $2.443 ; p=0.0849$; Age $F_{(3,28)}=0.8184 ; p=0.4946$; Genotype $\left.F_{(1,28)}=0.2668 ; p=0.6095\right]$ or GL [Two-way ANOVA (genotype vs. age): Interaction $F_{(3,28)}=2.054 ; p=0.1291$; Age $F_{(3,28)}=2.496 ; p=0.0803$; Genotype $F_{(1,28)}=0.005049 ; p=$ $0.9439]$.

\section{Analysis of Interneuron Markers}

Calbindin-positive neurons were mostly concentrated in the GL in both control (Figures 3A,C) and transgenic (Figures 3B,D) animals. No significant changes were observed with aging (Figures 3A,B vs. Figures 3C,D) or genotype (Figures 3A,C vs. 


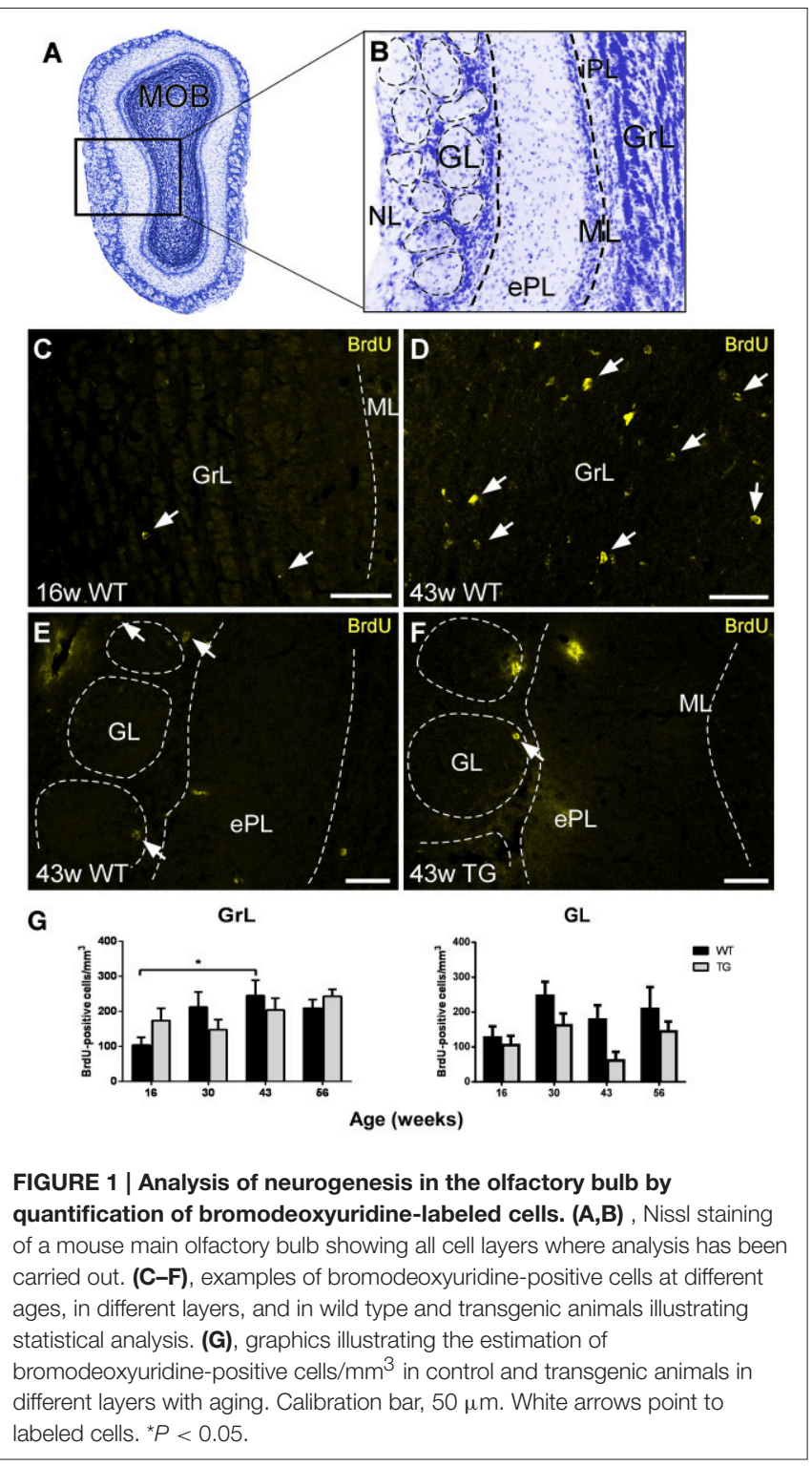

Figures 3B,D) as demonstrated statistically (Figure 3E) [Twoway ANOVA (genotype vs. age): Interaction $F_{(3,28)}=1.679$; $p=0.1940 ;$ Age $F_{(3,28)}=1.942 ; p=0.1457$; Genotype $\left.F_{(1,28)}=0.2197 ; p=0.6429\right]$.

Most parvalbumin-labeled neurons appeared in the ML/ePL in control (Figures 4A,C) and transgenic mice (Figures 4B,D). The expression appear to increase from 16 (Figures 4A,B) to 56 (Figures 4C,D) in both control and transgenic animals. Statistical analysis demonstrated a significant increase from 16 to 43 and 56 weeks in transgenic animals (Figure 4E). No changes were significant between control and transgenic animals [Twoway ANOVA (genotype vs. age): Interaction $F_{(3,28)}=2.026$; $p=0.1331 ;$ Age $F_{(3,28)}=3.617 ; p=0.0252$; Genotype $\left.F_{(1,28)}=0.6551 ; p=0.4251\right]$.

Calretinin-expressing cells were distributed in the $\mathrm{GrL} / \mathrm{iPL}$ and $\mathrm{ML} / \mathrm{ePL}$ - where positive mitral cells have been included in the analysis-, but particularly in the GL/NL in both control

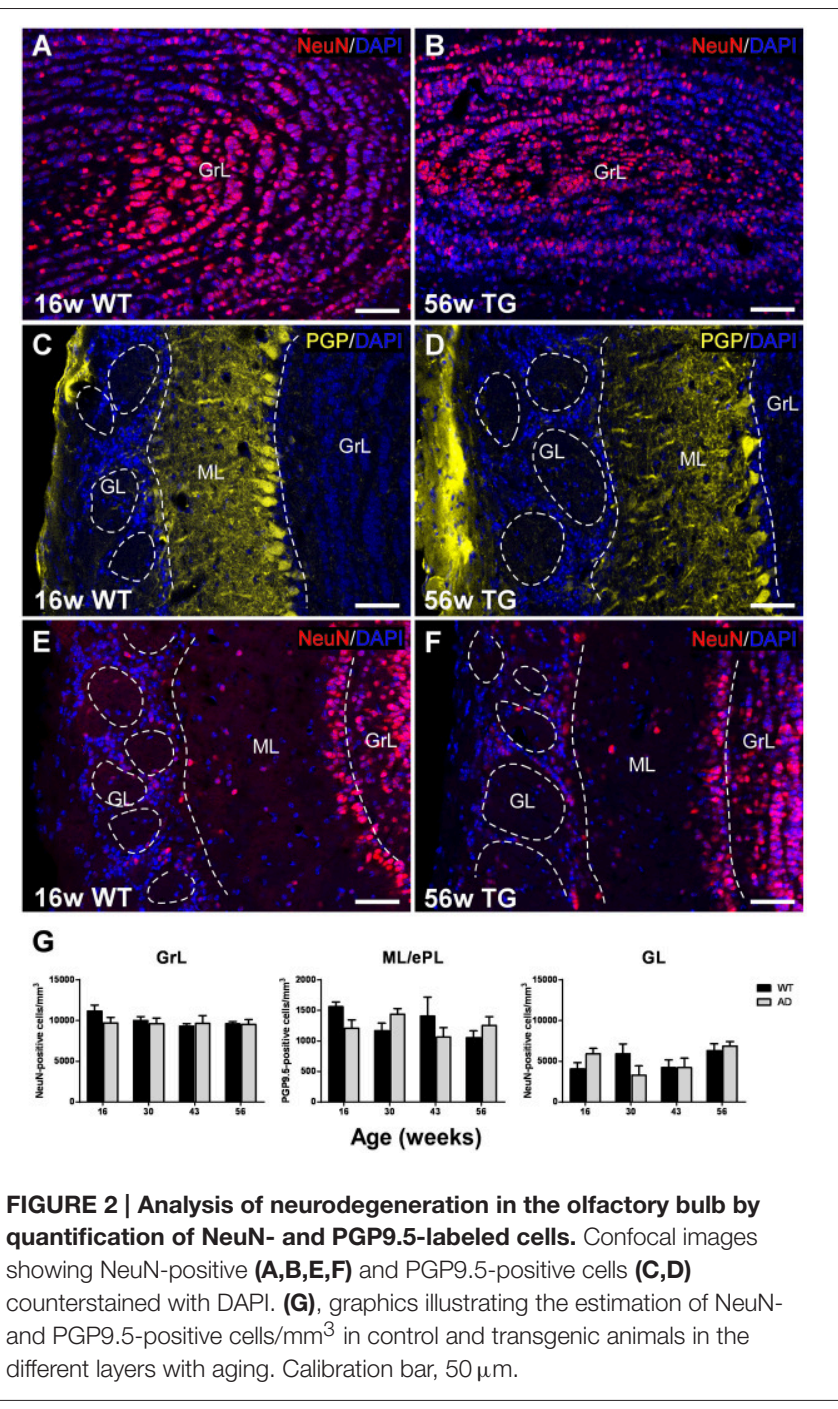

and transgenic animals (Figures 5A-F). In the GrL/iPL of transgenic animals, the expression significantly increased from 30 (Figure 5A) to 56 (Figure 5B) weeks (Figure 5G) [Twoway ANOVA (genotype vs. age): Interaction $F_{(3,28)}=3.334$; $p=0.0336$; Age $F_{(3,28)}=1.875 ; p=0.1568$; Genotype $F_{(1,28)}=$ $1.481 ; p=0.2338]$. At 30 weeks, the expression in control animals was higher as compared to transgenic animals [ $T$-test two tailed control vs. transgenic: $\left.t_{7}=2.873 ; p=0.0239\right]$. In the ML/ePL of control animals, the expression significantly decreased from 16 (Figure 5C) to 30, 43, and 56 (Figure 5E) weeks (Figure 5G); and, at 16 weeks, the expression in control animals (Figure 5C) was higher as compared to transgenic (Figure 5D) animals (Figure 5F) [Two-way ANOVA (genotype vs. age): Interaction $F_{(3,28)}=3.208 ; p=0.0382 ;$ Age $F_{(3,28)}=6.341 ; p=0.0020$; Genotype $F_{(1,28)}=2.021 ; p=0.1662$ ] [ $T$-test two tailed control vs. transgenic: $p>0.05$ ]. In the GL/NL, no significant changes with aging or genotype were detected (Figures 5A-G) [Twoway ANOVA (genotype vs. age): Interaction $F_{(3,28)}=1.031$; $p=0.3940 ;$ Age $F_{(3,28)}=0.7346 ; p=0.5402$; Genotype $\left.F_{(1,28)}=0.1791 ; p=0.6754\right]$. 

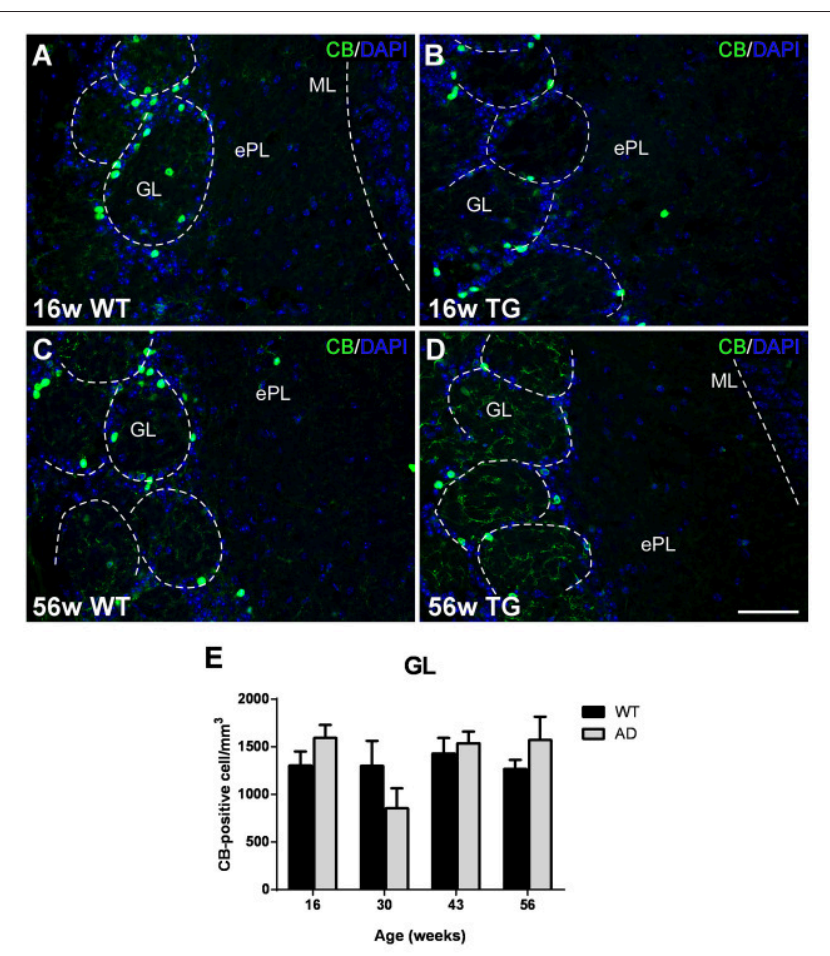

FIGURE 3 | Vulnerability analysis of calbindin-expressing cells in the olfactory bulb. (A-D), Confocal images showing calbindin-positive cells in the glomerular layer of control and transgenic animals at different ages. (E), graphics illustrating the estimation of calbindin-positive cells $/ \mathrm{mm}^{3}$ in control and transgenic animals in the glomerular layer with aging. Calibration bar, $50 \mu \mathrm{m}$.

Finally, regarding somatostatin-expression, cell bodies were mostly present in the ePL (Figure 6A) and only occasionally in the GrL (Figure 6C). Cell bodies degenerate with the disease leaving cell debris (Figure 6A vs. Figure 6B and Figure 6C vs. Figure 6D). To address, if cell bodies and/or fibers were reduced in different degree, we quantified the $\%$ of area within each region of interest occupied by somatostatin labeling (including cell bodies plus fibers) and total somatostatin positive cell bodies in the ePL. In this area, the reduction in \% of area occupied by fibers and cell bodies starts early (at 30 weeks of age) and the reduction of somatostatin cell bodies is even sooner (at 16 weeks of age), suggesting that soluble pathology focuses on cell bodies (see discussion) (Figure 6E). Analysis of positive fibers and cells in the ePL [Two-way ANOVA (genotype vs. age): Interaction $F_{(3,27)}=$ $2.308 ; p=0.0990$; Age $F_{(3,27)}=0.8809 ; p=0.4633$; Genotype $\left.F_{(1,27)}=10.61 ; p=0.0030\right]$, GrL [Two-way ANOVA (genotype vs. age): Interaction $F_{(3,27)}=2.027 ; p=0.1338$; Age $F_{(3,27)}=$ $2.864 ; p=0.0552$; Genotype $\left.F_{(1,27)}=22.68 ; p<0.0001\right]$ and cell bodies in the ePL [Two-way ANOVA (genotype vs. age): Interaction $F_{(3,27)}=0.9887 ; p=0.4129 ; \operatorname{Age} F_{(3,27)}=7.861 ; p=$ 0.0006 ; Genotype $\left.F_{(1,27)}=71.01 ; p<0.0001\right]$ reveal significant lower expression in transgenic vs. control animals (Figure 6E). Further, in transgenic animals, a significant decrease with aging was observed in the expression of fibers and cells in the GrL [Two-way ANOVA (genotype vs. age): Interaction $F_{(3,27)}=$

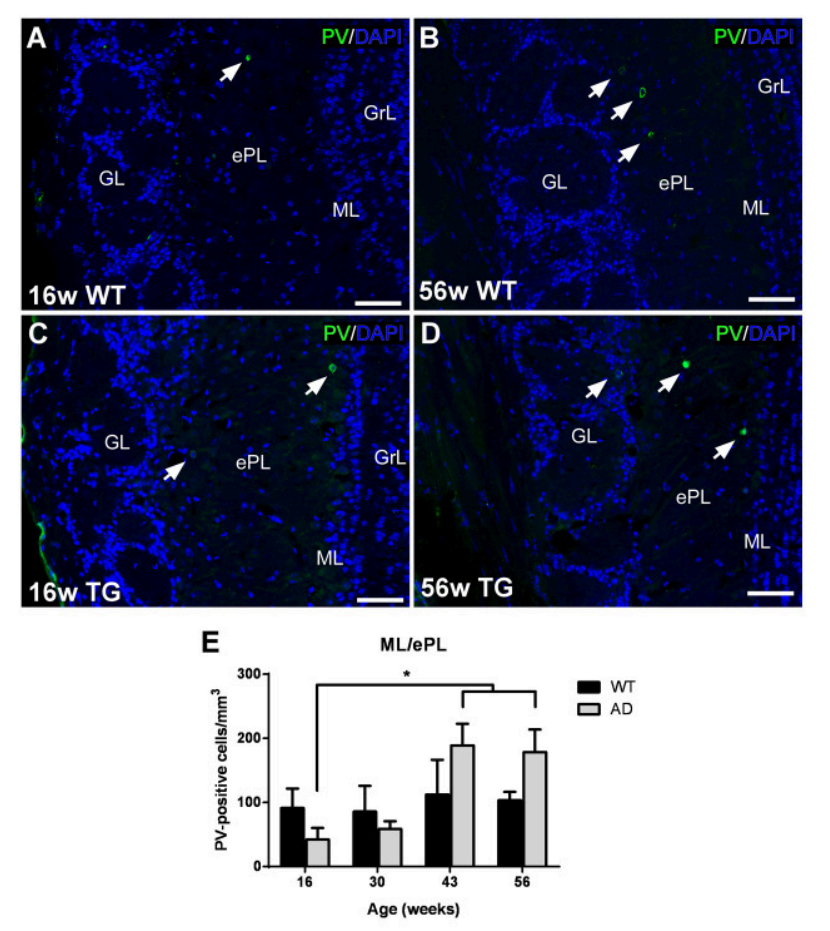

FIGURE 4 | Vulnerability analysis of parvalbumin-expressing cells in the olfactory bulb. (A-D), confocal images showing parvalbumin-positive cells in the mitral/external plexiform layer of control and transgenic animals at different ages. (E), Graphics illustrating the estimation of parvalbumin-positive cells $/ \mathrm{mm}^{3}$ in control and transgenic animals in the mitral/external plexiform layer with aging. Calibration bar, $50 \mu \mathrm{m}$. White arrows point to labeled cells. ${ }^{\star} P<0.05$.

$2.027 ; p=0.1338$; Age $F_{(3,27)}=2.864 ; p=0.0552$; Genotype $\left.F_{(1,27)}=22.68 ; p<0.0001\right]$ and in the expression of cell bodies in the ePL [Two-way ANOVA (genotype vs. age): Interaction $F_{(3,27)}$ $=0.9887 ; p=0.4129 ;$ Age $F_{(3,27)}=7.861 ; p=0.0006$; Genotype $\left.F_{(1,27)}=71.01 ; p<0.0001\right]$ (Figures 6E-G).

\section{Analysis of $A \beta$}

As expected in the transgenic model, $\mathrm{A} \beta$ aggregation increased over time, but mostly restricted to the granule cell layer (Figures 7A-E). Percentage of area occupied by A $\beta$ within GrL was significantly increased from 16 and 30 weeks vs. 43 and 56 weeks and from 43 to 56 weeks (Figure 7F) [One way ANOVA age: $\left.F_{(3,13)}=91.87, p<0.0001\right]$.

\section{Co-localization of $A \beta$, Interneuron Markers, and BrdU}

Since analysis of interneuron vulnerability revealed that calretinin-positive and, particularly, somatostatin-positive cells were decreased in transgenic animals, additional colocalization experiments were carried out to provide qualitative observations (see Supplementary Figure 2). Examples of somatostatin-positive cells with a dystrophic appearance (Supplementary Figure $2 \mathrm{~A}$ ) were placed in $\mathrm{A} \beta$ plaques (Supplementary Figure 2B) surrounded by $A \beta$ aggregates (Supplementary Figure 2C). 


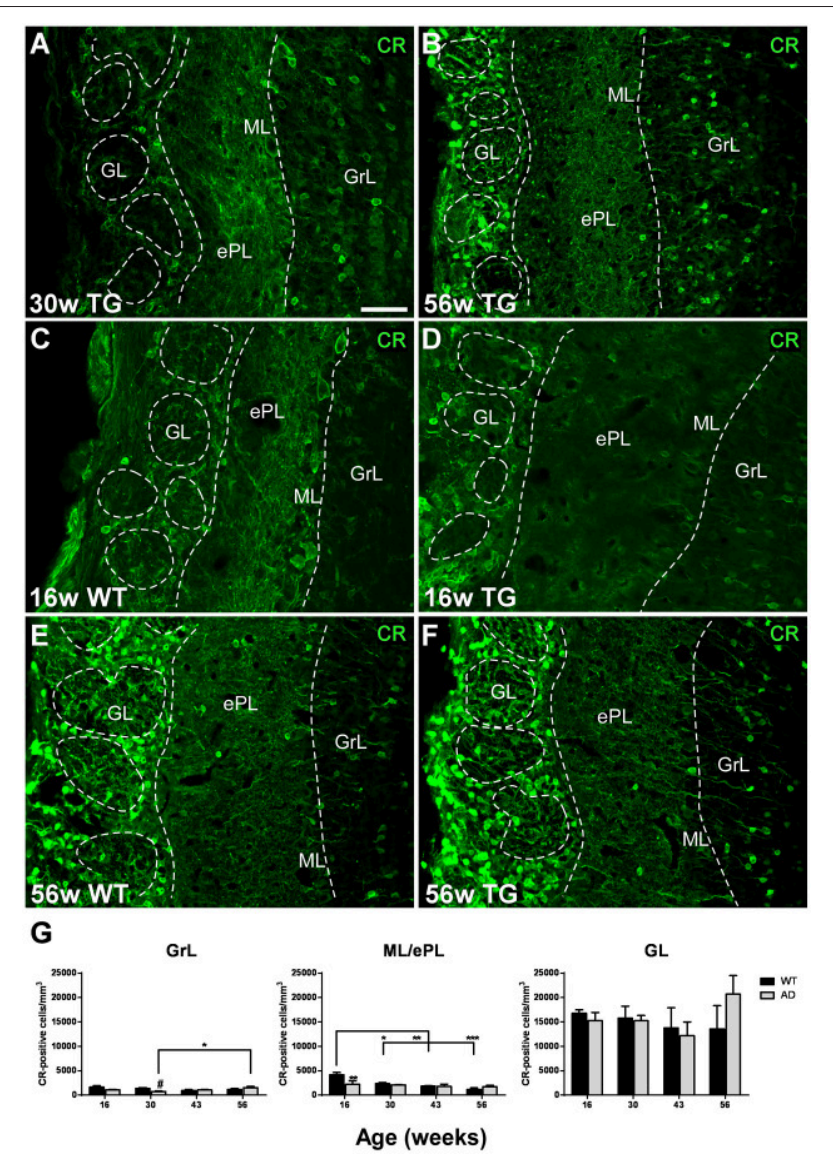

FIGURE 5 | Vulnerability analysis of calretinin-expressing cells in the olfactory bulb. (A-F), confocal images showing calretinin-positive cells in the different layers of control and transgenic animals at distinct ages. (G), graphics illustrating the estimation of calretinin-positive cells $/ \mathrm{mm}^{3}$ in control and transgenic animals in the different layers with aging. Calibration bar, $50 \mu \mathrm{m}$. ${ }^{\star} P<0.05,{ }^{\star \star} P<0.01,{ }^{\star \star \star} P<0.001$

Calretinin-positive cells (Supplementary Figure 2D) were also located in $\mathrm{A} \beta$ plaques (Supplementary Figures 2E,F).

The low rate of BrdU-labeled cells coexpressing interneuron markers prevented to carry out quantitative analysis. Only a small percentage of them were observed co-expressing somatostatin or calretinin (Supplementary Figure 3) and amyloid $\beta$ (see Supplementary Figure 4).

\section{DISCUSSION}

In the present report, neurogenesis, neurodegeneration, interneuron vulnerability, and amyloid $\beta$ involvement has been investigated in the $\mathrm{OB}$ of mouse model of $\mathrm{AD}$ and control animals over time. The main results include: neurogenesis increases with aging in the granule cell layer of control animals from 16 to 43 weeks. No neurodegeneration changes have been observed after quantifying NeuN or PGP9.5. Calbindin-expressing neurons remains unchanged. Parvalbumin-expressing neurons trend to increase with aging in transgenic animals. Calretinin-expressing neurons increase with aging in transgenic mice in the GrL and
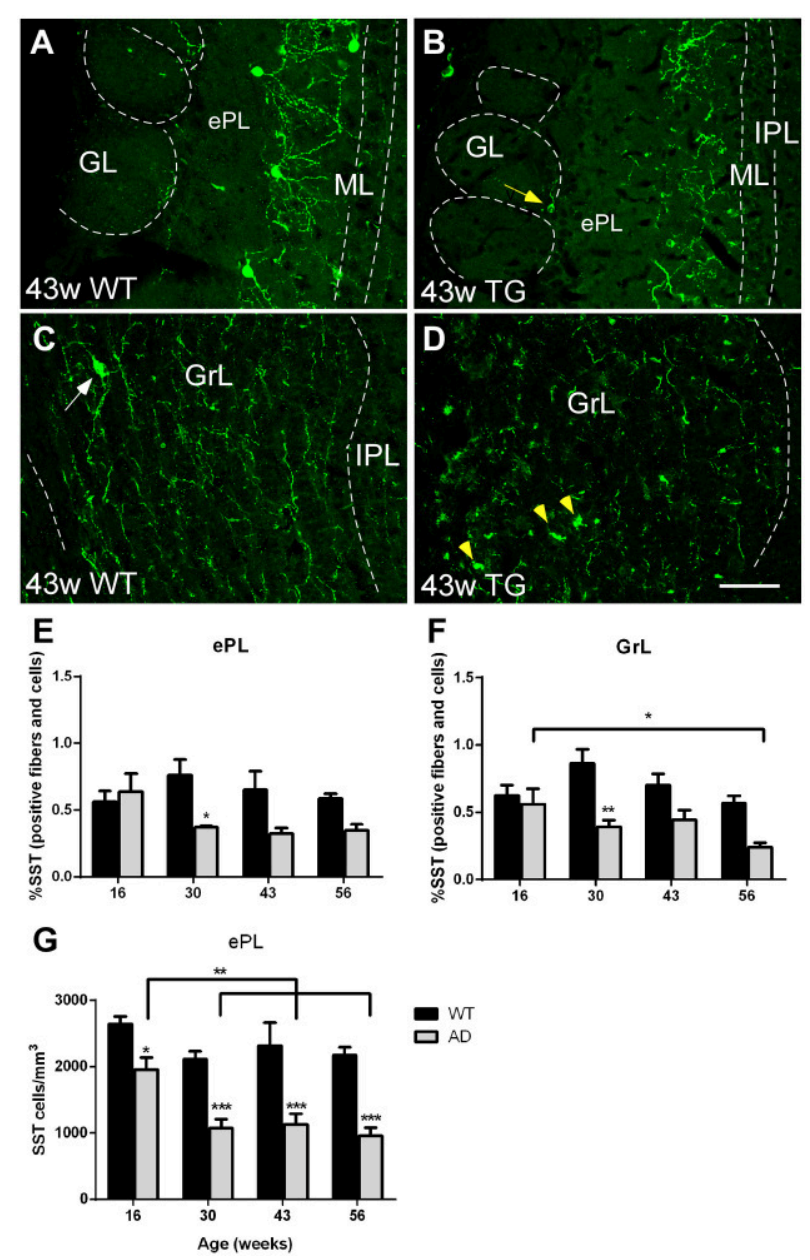

FIGURE 6 | Vulnerability analysis of somatostatin-expressing cells and fibers in the olfactory bulb. (A-D), Confocal images showing somatostatin-positive cells and fibers in the different layers of control and transgenic animals at distinct ages. (E-G), graphics illustrating both \% of area occupied by somatostatin cell bodies and fibers within ePL and GrL and the estimation of total somatostatin-positive in the ePL (cells $/ \mathrm{mm} 3$ ) in control and transgenic animals. Calibration bar, $50 \mu \mathrm{m}$. White arrows point to labeled cells. Yellow arrow point to labeled periglomerular cell and yellow arrowheads to cell debries. ${ }^{\star} P<0.05,{ }^{\star \star} P<0.01,{ }^{* \star *} P<0.001$.

decrease in control animals in the ML and it is higher in control as compared to transgenic animals at given ages. Somatostatinexpressing neurons of transgenic mice decrease with aging and abruptly as compared to controls. Amyloid $\beta$ aggregates with aging in the granule cell layer, which may be related to the particular involvement of somatostatin-expressing cells.

Therefore, neurogenesis in transgenic animals, in contrast to control animals, do not increase with aging. Regarding interneuron vulnerability, calbindin expression is not altered, parvalbumin expression is increased, calretinin increases in transgenic and decreases in control animals and somatostatin is strongly reduced with aging and in transgenic animals as compared to controls. This evidences differential vulnerability among interneuron pupulations which may be related to $\mathrm{A} \beta$ pathology. 

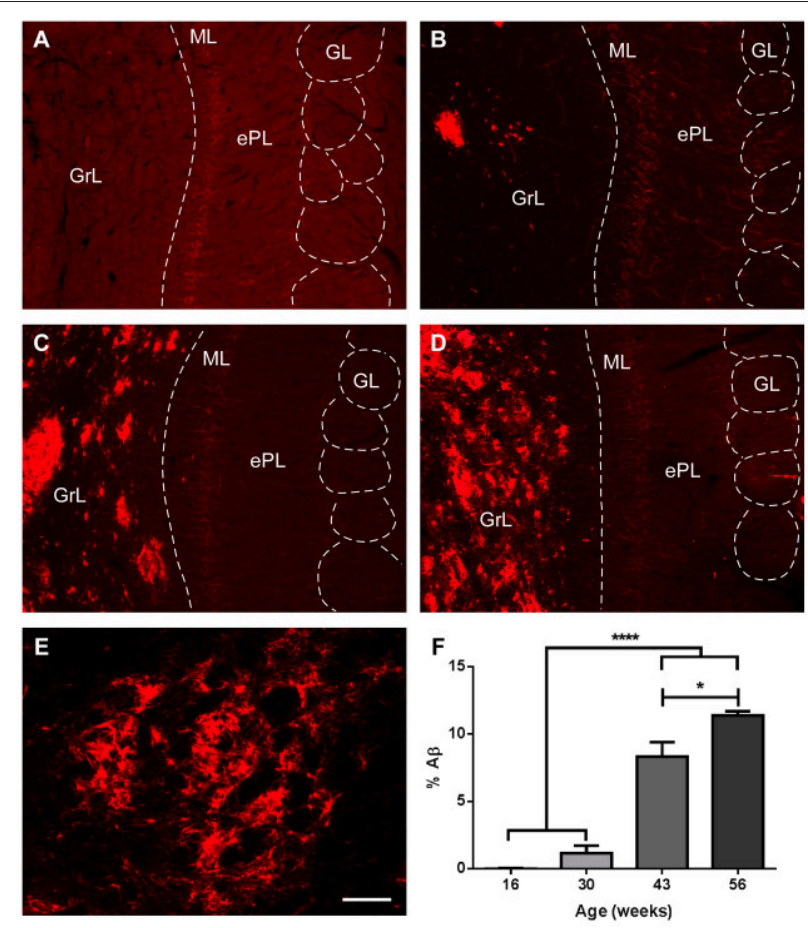

FIGURE 7 | Amyloid $\beta$ aggregation over time in the olfactory bulb of transgenic animals. (A-D), \%A $\beta$ aggregates in transgenic mice at 16,30 , 43 , and 56 weeks, respectively. (E), high power of a plaque. (F), graphics illustrating $\%$ of area occupied by $A \beta$, virtually restricted to the granule cell layer. Calibration bar for (A-D), $80 \mu \mathrm{m}$, for E, $20 \mu \mathrm{m}$. ${ }^{*} P<0.05$, ${ }^{* * \star *} P<0.0001$.

\section{Neurogenesis in Alzheimer's Disease}

Fifty years after the first seminal report of neurogenesis in the adult brain (Altman and Das, 1965), the specific role of newborn cells integrated in the DG (Kempermann et al., 2015) or OB (Lepousez et al., 2015) is not fully understood. Growing interest has focused on therapeutic opportunities, particularly regarding neurodegenerative diseases, in particular Huntington's, Parkinson's, and Alzheimer's diseases (Kaneko and Sawamoto, 2009; Lazarov et al., 2010; Winner et al., 2011; Winner and Winkler, 2015).

In the case of $\mathrm{AD}$, there is a number of molecules implicated in its etiology that also play a key role in adult neurogenesis such as ApoE, PS1, APP, and its metabolites (Lazarov and Marr, 2010; Mu and Gage, 2011). In particular, it has been demonstrated that soluble APP $\alpha$ regulates neural progenitor cell proliferation and that miscleavage of APP could greatly influence in developmental and postnatal neurogenesis, which could contribute to symptomatic cognitive deficits in $\mathrm{AD}$ (Lazarov and Demars, 2012).

Data on neurogenic rates are quite variable depending on species, age, environment, and disease. Neurogenesis occurs in postnatal and adult rodents and postnatal humans (Lazarov and Marr, 2013) but, in adult humans, there is substantial hippocampal and striatal neurogenesis and it is no detectable in the OB (Bergmann et al., 2015). There is a general agreement regarding reduction of neurogenesis with aging (Hamilton et al.,
2013), which contrast with our present results in control animals. In the granule cell layer, it has been described a decreasing number of new-born cell with aging (Petrenau and AlvarezBuylla, 2002; Winner et al., 2002), which does not match our results. It is interesting to note that previous reports show nonsignificant peaks at 20 (Petrenau and Alvarez-Buylla, 2002) and 24 weeks (Winner et al., 2002) and ours results a significant peak at 43 weeks. Likely these discrepancies are due methodological differences regarding the method used: BrdU vs. $\left[{ }^{3} \mathrm{H}\right]$-thymidine or BrdU administration in 1 day vs. 4 consecutive days. In diseased brains, however, data are highly variable depending on the pathology analyzed. Even in $\mathrm{AD}$, data are controversial depending on model used, experimental conditions, markers or area studied (Lazarov and Marr, 2010; Winner et al., 2011).

Reports in the double APP/PS1 transgenic model show a reduced hippocampal neurogenesis. Niidome and colleagues describe no reduction of proliferating cells in the SVZ, but a significant decrease in the SGZ (Niidome et al., 2008). Verret and colleagues report that, although hippocampal proliferation was unaffected, survival of newborn cells 4 weeks later was dramatically diminished (Verret et al., 2007). Conversely, Demars and colleagues, conclude that this neurogenesis impairment occurs early in life long before amyloid deposition (Demars et al., 2010). Interestingly, it has been reported that the reduction in neuroblasts was restricted to the hippocampal but not to the OB neurogenic system (Zhang et al., 2007). In fact, our results (Figure 1) show no significant reduction in the number of BrdU-labeled cells in the glomerular layer in APP/PS1 model.

\section{Amyloid $\beta$ Proteinopathy and Interneuron Population Involvement}

Alzheimer disease is a neurodegenerative disease and as such, neuronal loss is expected. It is difficult, however, to distinguish neurodegenerative changes that accompany normal aging (Attems et al., 2015) from those that characterize AD. In the hippocampus, for instance, a significant cell loss was reported in CA1 in Alzheimer's patients, whereas there was almost no neuron loss in the normal aging group (West et al., 1994). In the $\mathrm{OB}$, it has been reported that the total number of cells and the number of mitral cells were the same for controls and patients, but the volume of the bulb and the number of cells in the anterior olfactory nucleus was reduced up to $75 \%$ in younger patients (Ter Laak et al., 1994). Our results on the number of NeuNand PGP9.5-positive cells in the different layers of the bulb reveal no neuronal loss with aging in both control and transgenic mice suggesting that volume reduction must be due to neuropil reorganization and shrinkage.

Amyloid $\beta$ aggregation in the $\mathrm{OB}$ has been described as an early event in the neuropathology of AD (Ohm and Braak, 1987; Jellinger and Attems, 2005; Attems et al., 2012, 2014). In APP/PS1 mouse model, $A \beta$ aggregation has been reported in the olfactory cortex (Saiz-Sanchez et al., 2012) as well as in the OB and anterior olfactory nucleus (Saiz-Sanchez et al., 2013). The present data are in agreement with these reports showing an accumulative aggregation of $\mathrm{A} \beta$ plaques in the $\mathrm{OB}$, but restricted to the granule cell layer. 
It has been described that the different interneuron populations show differential expression and vulnerability in the disease as compared to controls in given areas (Iritani et al., 2001; Saiz-Sanchez et al., 2016) and not in others (Leuba et al., 1998). In human tissue, it has been reported a $50 \%$ reduction in somatostatin expression in the anterior olfactory nucleus matching a high co-localization with $A \beta$ (Saiz-Sanchez et al., 2010). In the piriform cortex, somatostatin and calretinin expression was reduced showing high co-localization with $\mathrm{A} \beta$, whereas parvalbumin expression was increased (SaizSanchez et al., 2015) in agreement with our present results. It is interesting to note that not only $A \beta$ aggregates, but soluble $\mathrm{A} \beta$ - not detected with the used antibody-is particularly toxic for neurons. Other authors describes that calretinin-positive cells are resistant to neurodegeneration in the human temporal cortex (Fonseca and Soriano, 1995) — which matches the light increase described herein-and other authors reports differential vulnerability of parvalbumin-positive cells depending on the hippocampal field (Brady and Mufson, 1997) or entorhinal cortex (Solodkin et al., 1996; Mikkonen et al., 1999). In the olfactory cortex of APP/PS1 model, similar results were found being somatostatin and calretinin expression severely reduced and calbindin and parvalbumin expression later and only moderately reduced (Saiz-Sanchez et al., 2012). It is interesting to note that previous reports in our laboratory (Saiz-Sanchez et al., 2012, 2013) studied groups up to 8 months of age, whereas in the present report these observations were extended up to 56 weeks. Therefore, present data are in agreement with previous reports and enlarge previous descriptions reveling, for instance, a late increase of parvalbumin expression that could constitute a compensatory mechanism of some calcium binding protein expressing interneuron populations. In the $\mathrm{OB}$, previous results

\section{REFERENCES}

Altman, J. (1962). Are new neurons formed in the brains of adult mammals? Science 135, 1127-1128. doi: 10.1126/science.135.3509.1127

Altman, J., and Das, G. D. (1965). Autoradiographic and histological evidence of postnatal hippocampal neurogenesis in rats. J. Comp. Neurol. 124, 319-335. doi: 10.1002/cne.901240303

Attems, J., Thomas, A., and Jellinger, K. (2012). Correlations between cortical and subcortical tau pathology. Neuropathol. Appl. Neurobiol. 38, 582-590. doi: 10.1111/j.1365-2990.2011.01244.x

Attems, J., Walker, L., and Jellinger, K. A. (2014). Olfactory bulb involvement in neurodegenerative diseases. Acta Neuropathol. 127, 459-475. doi: 10.1007/s00401-014-1261-7

Attems, J., Walker, L., and Jellinger, K. A. (2015). Olfaction and aging: a minireview. Gerontology 61, 485-490. doi: 10.1159/000381619

Bagley, J., Larocca, G., Jimenez, D. A., and Urban, N. N. (2007). Adult neurogenesis and specific replacement of interneuron subtypes in the mouse main olfactory bulb. BMC Neurosci. 8:92. doi: 10.1186/1471-2202-8-92

Ballard, C., Gauthier, S., Corbett, A., Brayne, C., Aarsland, D., and Jones, E. (2011). Alzheimer's disease. Lancet 377, 1019-1031. doi: 10.1016/S01406736(10)61349-9

Bergmann, O., Spalding, K. L., and Frisen, J. (2015). Adult Neurogenesis in Humans. Cold Spring Harb. Perspect. Biol. 7:a018994. doi: 10.1101/cshperspect.a018994

Bianchi, P., Bettini, S., Guidi, S., Ciani, E., Trazzi, S., Stagni, F., et al. (2014). Age-related impairment of olfactory bulb neurogenesis in the were similar (Saiz-Sanchez et al., 2013) and in agreement with present data were calretinin- and, particularly somatostatin-, expression was reduced in transgenic as compared to control animals.

Regarding Alzheimer's etiology, it has been described that decreased somatostatin expression may predispose to $A \beta$ accumulation. This finding has raised the possibility that somatostatin receptor agonists may be of therapeutic value in $\mathrm{AD}$ (Hama and Saido, 2005; Iwata et al., 2005; Saito et al., 2005; Saido and Iwata, 2006). The present results further support the idea that somatostatin expressing neurons are early and preferentially involved by $\mathrm{A} \beta$ pathology in $\mathrm{AD}$ and that this could be on its etiology.

\section{AUTHOR CONTRIBUTIONS}

CD experiments and analysis. DS, IU, AF analysis and quantification. AM coordination and writing.

\section{ACKNOWLEDGMENTS}

This study was supported by the Spanish Ministry of Science and Innovation-FEDER: grant BFU2010-15729; Spanish Ministry of Economy and Competitiveness-FEDER: grant SAF2014-52300R; Autonomous Government of Castilla-La Mancha-FEDER: grant PEIC-2014-006-P.

\section{SUPPLEMENTARY MATERIAL}

The Supplementary Material for this article can be found online at: http://journal.frontiersin.org/article/10.3389/fnins. 2016.00227
Ts65Dn mouse model of Down syndrome. Exp. Neurol. 251, 1-11. doi: 10.1016/j.expneurol.2013.10.018

Braak, H., Alafuzoff, I., Arzberger, T., Kretzschmar, H., and Del Tredici, K. (2006). Staging of Alzheimer disease-associated neurofibrillary pathology using paraffin sections and immunocytochemistry. Acta Neuropathol. 112, 389-404. doi: 10.1007/s00401-006-0127-z

Braak, H., and Braak, E. (1991). Neuropathological stageing of Alzheimer-related changes. Acta Neuropathol. 82, 239-259. doi: 10.1007/BF00308809

Braak, H., and Del Trecidi, K. (2015). Neuroanatomy and pathology of sporadic Alzheimer's disease. Adv. Anat. Embryol. Cell Biol. 215, 1-162. doi: 10.1007/978-3-319-12679-1_1

Brady, D. R., and Mufson, E. J. (1997). Parvalbumin-immunoreactive neurons in the hippocampal formation of Alzheimer's diseased brain. Neuroscience 80, 1113-1125. doi: 10.1016/S0306-4522(97)0 0068-7

De La Rosa-Prieto, C., Saiz-Sanchez, D., Ubeda-Bañon, I., Argandoña-Palacios, L., Garcia-Muñozguren, S., and Martinez-Marcos, A. (2009). Fate of marginal neuroblasts in the vomeronasal epithelium of adult mice. J. Comp. Neurol. 517, 723-736. doi: 10.1002/cne.22188

Demars, M., Hu, Y. S., Gadadhar, A., and Lazarov, O. (2010). Impaired neurogenesis is an early event in the etiology of familial Alzheimer's disease in transgenic mice. J. Neurosci. Res. 88, 2103-2117. doi: 10.1002/jnr. 22387

Deng, W., Aimone, J. B., and Gage, F. H. (2010). New neurons and new memories: how does adult hippocampal neurogenesis affect learning and memory? Nat. Rev. Neurosci. 11, 339-350. doi: 10.1038/nrn2822 
Devanand, D. P., Lee, S., Manly, J., Andrews, H., Schupf, N., Doty, R. L., et al. (2015). Olfactory deficits predict cognitive decline and Alzheimer dementia in an urban community. Neurology 84, 182-189. doi: 10.1212/WNL.0000000000001132

Fonseca, M., and Soriano, E. (1995). Calretinin-immunoreactive neurons in the normal human temporal cortex and in Alzheimer's disease. Brain Res. 691, 83-91. doi: 10.1016/0006-8993(95)00622-W

Goedert, M., and Spillantini, M. G. (2006). A century of Alzheimer's disease. Science 314, 777-781. doi: 10.1126/science.1132814

Hama, E., and Saido, T. C. (2005). Etiology of sporadic Alzheimer's disease: somatostatin, neprilysin, and amyloid beta peptide. Med. Hypotheses 65, 498-500. doi: 10.1016/j.mehy.2005.02.045

Hamilton, L. K., Joppé, S. E., M Cochard, L., and Fernandes, K. J. (2013). Aging and neurogenesis in the adult forebrain: what we have learned and where we should go from here. Eur. J. Neurosci. 37, 1978-1986. doi: 10.1111/ejn.12207

Iritani, S., Niizato, K., and Emson, P. C. (2001). Relationship of calbindin D28Kimmunoreactive cells and neuropathological changes in the hippocampal formation of Alzheimer's disease. Neuropathology 21, 162-167. doi: 10.1046/j.1440-1789.2001.00393.x

Iwata, N., Higuchi, M., and Saido, T. C. (2005). Metabolism of amyloidbeta peptide and Alzheimer's disease. Pharmacol. Ther. 108, 129-148. doi: 10.1016/j.pharmthera.2005.03.010

Jahn, H. (2013). Memory loss in Alzheimer's disease. Dialogues Clin. Neurosci. 15, 445-454.

Jankowsky, J. L., Slunt, H. H., Gonzales, V., Jenkins, N. A., Copeland, N. G., and Borchelt, D. R. (2004). APP processing and amyloid deposition in mice haplo-insufficient for presenilin 1. Neurobiol. Aging 25, 885-892. doi: 10.1016/j.neurobiolaging.2003.09.008

Jankowsky, J. L., Slunt, H. H., Ratovitski, T., Jenkins, N. A., Copeland, N. G., and Borchelt, D. R. (2001). Co-expression of multiple transgenes in mouse CNS: a comparison of strategies. Biomol. Eng. 17, 157-165. doi: 10.1016/S13890344(01)00067-3

Jellinger, K. A., and Attems, J. (2005). Alzheimer pathology in the olfactory bulb. Neuropathol. Appl. Neurobiol. 31, 203. doi: 10.1111/j.1365-2990.2004.00619.x

Kaneko, N., and Sawamoto, K. (2009). Adult neurogenesis and its alteration under pathological conditions. Neurosci. Res. 63, 155-164. doi: 10.1016/j.neures.2008.12.001

Kempermann, G., Song, H., and Gage, F. H. (2015). Neurogenesis in the adult hippocampus. Cold Spring Harb. Perspect. Med. 5:a018812. doi: $10.1101 /$ cshperspect.a018812

Lazarov, O., and Demars, M. P. (2012). All in the family: how the APPs regulate neurogenesis. Front. Neurosci. 6:81. doi: 10.3389/fnins.2012.00081

Lazarov, O., and Marr, R. A. (2010). Neurogenesis and Alzheimer's disease: at the crossroads. Exp. Neurol. 223, 267-281. doi: 10.1016/j.expneurol.2009.08.009

Lazarov, O., and Marr, R. A. (2013). Of mice and men: neurogenesis, cognition and Alzheimer's disease. Front. Aging Neurosci. 5:43. doi: 10.3389/fnagi.2013.00043

Lazarov, O., Mattson, M. P., Peterson, D. A., Pimplikar, S. W., and Van Praag, H. (2010). When neurogenesis encounters aging and disease. Trends Neurosci. 33, 569-579. doi: 10.1016/j.tins.2010.09.003

Lepousez, G., Nissant, A., and Lledo, P. M. (2015). Adult neurogenesis and the future of the rejuvenating brain circuits. Neuron 86, 387-401. doi: 10.1016/j.neuron.2015.01.002

Lepousez, G., Valley, M. T., and Lledo, P. M. (2013). The impact of adult neurogenesis on olfactory bulb circuits and computations. Annu. Rev. Physiol. 75, 339-363. doi: 10.1146/annurev-physiol-030212-183731

Leuba, G., Kraftsik, R., and Saini, K. (1998). Quantitative distribution of parvalbumin, calretinin, and calbindin D-28k immunoreactive neurons in the visual cortex of normal and Alzheimer cases. Exp. Neurol. 152, 278-291. doi: 10.1006/exnr.1998.6838

Levi, O., and Michaelson, D. M. (2007). Environmental enrichment stimulates neurogenesis in apolipoprotein E3 and neuronal apoptosis in apolipoprotein E4 transgenic mice. J. Neurochem. 100, 202-210. doi: 10.1111/j.14714159.2006.04189.x

Lois, C., and Alvarez-Buylla, A. (1994). Long-distance neuronal migration in the adult mammalian brain. Science 264, 1145-1148. doi: 10.1126/science.8178174

Luskin, M. B. (1993). Restricted proliferation and migration of postnatally generated neurons derived from the forebrain subventricular zone. Neuron 11, 173-189. doi: 10.1016/0896-6273(93)90281-U
Martinez-Marcos, A., Jia, C., Quan, W., and Halpern, M. (2005). Neurogenesis, migration, and apoptosis in the vomeronasal epithelium of adult mice. J. Neurobiol. 63, 173-187. doi: 10.1002/neu.20128

Martínez-Marcos, A., Ubeda-Bañón, I., Deng, L., and Halpern, M. (2000a). Neurogenesis in the vomeronasal epithelium of adult rats: evidence for different mechanisms for growth and neuronal turnover. J. Neurobiol. 44, 423-435. doi: 10.1002/1097-4695(20000915)44:43.0.CO;2-H

Martínez-Marcos, A., Ubeda-Bañón, I., and Halpern, M. (2000b). Cell turnover in the vomeronasal epithelium: evidence for differential migration and maturation of subclasses of vomeronasal neurons in the adult opossum. $J$. Neurobiol. 43, 50-63. doi: 10.1002/(SICI)1097-4695(200004)43:13.0.CO;2-N

Mikkonen, M., Alafuzoff, I., Tapiola, T., Soininen, H., and Miettinen, R. (1999). Subfield- and layer-specific changes in parvalbumin, calretinin and calbindinD28K immunoreactivity in the entorhinal cortex in Alzheimer's disease. Neuroscience 92, 515-532. doi: 10.1016/S0306-4522(99)00047-0

$\mathrm{Mu}, \mathrm{Y}$. , and Gage, F. H. (2011). Adult hippocampal neurogenesis and its role in Alzheimer's disease. Mol. Neurodegener. 6:85. doi: 10.1186/1750-1326-6-85

Niidome, T., Taniuchi, N., Akaike, A., Kihara, T., and Sugimoto, H. (2008). Differential regulation of neurogenesis in two neurogenic regions of APPswe/PS1dE9 transgenic mice. Neuroreport 19, 1361-1364. doi: 10.1097/WNR.0b013e32830e6dd6

Ohm, T. G., and Braak, H. (1987). Olfactory bulb changes in Alzheimer's disease. Acta Neuropathol. 73, 365-369. doi: 10.1007/BF00688261

Petrenau, L., and Alvarez-Buylla, A. (2002). Maturation and death of adult-born olfactory bulb granule neurons: role on olfaction. J. Neurosci. 22, 6106-6113.

Reiman, E. M. (2014). Alzheimer's disease and other dementias: advances in 2013. Lancet Neurol. 13, 3-5. doi: 10.1016/S1474-4422(13)70257-6

Saido, T. C., and Iwata, N. (2006). Metabolism of amyloid beta peptide and pathogenesis of Alzheimer's disease. Towards presymptomatic diagnosis, prevention and therapy. Neurosci. Res. 54, 235-253. doi: 10.1016/j.neures.2005.12.015

Saito, T., Iwata, N., Tsubuki, S., Takaki, Y., Takano, J., Huang, S. M., et al. (2005). Somatostatin regulates brain amyloid beta peptide Abeta42 through modulation of proteolytic degradation. Nat. Med. 11, 434-439. doi: 10.1038/nm1206

Saiz-Sanchez, D., De La Rosa-Prieto, C., Ubeda-Bañon, I., and MartinezMarcos, A. (2013). Interneurons and beta-amyloid in the olfactory bulb, anterior olfactory nucleus and olfactory tubercle in APPxPS1 transgenic mice model of Alzheimer's disease. Anat. Rec. (Hoboken). 296, 1413-1423. doi: $10.1002 / \mathrm{ar} .22750$

Saiz-Sanchez, D., De La Rosa-Prieto, C., Ubeda-Banon, I., and Martinez-Marcos, A. (2015). Interneurons, tau and amyloid-beta in the piriform cortex in Alzheimer's disease. Brain Struct. Funct. 220, 2011-2025. doi: 10.1007/s00429014-0771-3

Saiz-Sanchez, D., Flores-Cuadrado, A., Ubeda-Bañon, I., De La RosaPrieto, C., and Martinez-Marcos, A. (2016). Interneurons in the human olfactory system in Alzheimer's disease. Exp. Neurol. 276, 13-21. doi: 10.1016/j.expneurol.2015.11.009

Saiz-Sanchez, D., Ubeda-Bañon, I., De La Rosa-Prieto, C., Argandoña-Palacios, L., Garcia-Muñozguren, S., Insausti, R., et al. (2010). Somatostatin, tau, and beta-amyloid within the anterior olfactory nucleus in Alzheimer disease. Exp. Neurol. 223, 347-350. doi: 10.1016/j.expneurol.2009.06.010

Saiz-Sanchez, D., Ubeda-Banon, I., De La Rosa-Prieto, C., and Martinez-Marcos, A. (2012). Differential expression of interneuron populations and correlation with amyloid-beta deposition in the olfactory cortex of an AbetaPP/PS1 transgenic mouse model of Alzheimer's disease. J. Alzheimers. Dis. 31, 113-129. doi: 10.3233/JAD-2012-111889

Solodkin, A., Veldhuizen, S. D., and Van Hoesen, G. W. (1996). Contingent vulnerability of entorhinal parvalbumin-containing neurons in Alzheimer's disease. J. Neurosci. 16, 3311-3321.

Ter Laak, H. J., Renkawek, K., and Van Workum, F. P. (1994). The olfactory bulb in Alzheimer disease: a morphologic study of neuron loss, tangles, and senile plaques in relation to olfaction. Alzheimer Dis. Assoc. Disord. 8, 38-48. doi: 10.1097/00002093-199408010-00007

Van Groen, T., Kiliaan, A. J., and Kadish, I. (2006). Deposition of mouse amyloid beta in human APP/PS1 double and single AD model transgenic mice. Neurobiol. Dis. 23, 653-662. doi: 10.1016/j.nbd.2006. 05.010 
Verret, L., Jankowsky, J. L., Xu, G. M., Borchelt, D. R., and Rampon, C. (2007). Alzheimer's-type amyloidosis in transgenic mice impairs survival of newborn neurons derived from adult hippocampal neurogenesis. J. Neurosci. 27, 6771-6780. doi: 10.1523/JNEUROSCI.5564-06.2007

West, M. J., Coleman, P. D., Flood, D. G., and Troncoso, J. C. (1994). Differences in the pattern of hippocampal neuronal loss in normal ageing and Alzheimer's disease. Lancet 344, 769-772. doi: 10.1016/S0140-6736(94)92338-8

Winner, B., Cooper-Kuhn, C. M., Aigner, R., Winkler, J., and Kuhn, H. G. (2002). Long-term survival and cell death of newly generated neurons in the adult rat olfactory bulb. Eur. J. Neurosci. 16, 1681-1689. doi: 10.1046/j.14609568.2002.02238.x

Winner, B., Kohl, Z., and Gage, F. H. (2011). Neurodegenerative disease and adult neurogenesis. Eur. J. Neurosci. 33, 1139-1151. doi: 10.1111/j.14609568.2011.07613.x

Winner, B., and Winkler, J. (2015). Adult neurogenesis in neurodegenerative diseases. Cold Spring Harb. Perspect. Biol. 7:a021287. doi: 10.1101/cshperspect. a021287
Zhang, C., Mcneil, E., Dressler, L., and Siman, R. (2007). Long-lasting impairment in hippocampal neurogenesis associated with amyloid deposition in a knockin mouse model of familial Alzheimer's disease. Exp. Neurol. 204, 77-87. doi: 10.1016/j.expneurol.2006.09.018

Conflict of Interest Statement: The authors declare that the research was conducted in the absence of any commercial or financial relationships that could be construed as a potential conflict of interest.

Copyright (c) 2016 De la Rosa-Prieto, Saiz-Sanchez, Ubeda-Banon, FloresCuadrado and Martinez-Marcos. This is an open-access article distributed under the terms of the Creative Commons Attribution License (CC BY). The use, distribution or reproduction in other forums is permitted, provided the original author(s) or licensor are credited and that the original publication in this journal is cited, in accordance with accepted academic practice. No use, distribution or reproduction is permitted which does not comply with these terms. 